\title{
The influence of money and the rate of interest on the rate of inflation in a financially repressed economy: the case of Turkey
}

\author{
SÜBIDEY TOGAN \\ Department of Economics, Bilkent University, Ankara, Turkey
}

This study takes as its task the explanation of movements in the rate of inflation. It seeks to discover the dynamic process by which monetary expansion and changes in the rate of interest have their effects upon the level of prices.

\section{INTRODUCTION}

Turkey provides a promising ground for the study of inflation in a financially repressed economy. Its rate of inflation has varied greatly over time. Inflation began during the second half of the 1950 s, reached $23.3 \%$ in 1957 and was reduced to $3.3 \%$ in 1960 . For the 1960 s, the rate of inflation was constrained within moderate limits. By 1969 the GNP deflator stood at 1.05 $(1968=1.0)$, but by 1977 it had reached 4.29 and by 1984 it was 74.67 . Furthermore, Turkey was a financially repressed economy until $1980 .{ }^{1}$ Since 1 July 1980 interest rates have in principle been set free, but the experience with an unregulated market in 1981 and the first half of 1982 , where several smaller banks offered higher than sustainable rates for time deposits in order to meet liquidity shortages has led Turkish authorities to fix interest rates uniformly at regular intervals. Thus, since 1980 financial repression has been reduced but not eliminated.

This study takes as its task the explanation of movements in the rate of inflation. It seeks to discover the dynamic process by which monetary expansion and changes in the rate of interest have their effects upon the level of prices.

The organization of the paper is as follows. Section II addresses the main methodological issues. Section III presents and discusses the estimation results. Simulation results and comparative dynamic analysis results are presented in Section IV. The principal conclusions appear in Section V. Data sources are given in the Appendix.

\footnotetext{
${ }^{1}$ In a financially repressed economy, markets for non-monetary government debt are largely non-existent. Also non-existent are significant markets for equities and commercial paper. Furthermore, interest rates (particularly deposit rates of interest) are held below their free market equilibrium level. Prior to 1980 all these characteristics were typical of financial markets in Turkey.
} 


\section{THE MODEL}

Consider the following model of the demand for money

$$
\begin{aligned}
& \ln (M / p)=a+\eta \ln y+\lambda R \\
& R=R N-\pi
\end{aligned}
$$

These two equations determine the price level $(p)$ and the real rate of return available from holding money $(R)$. The exogeneous variables are money $(M)$, real income $(y)$, the nominal rate of interest on money $(R N)$ and the expected rate of inflation $(\pi)^{2}$.

The money demand function (Equation 1a) represents the demand for real money balances as an increasing function of both the level of real income and real rate of return available from holding money, and Equation $1 \mathrm{~b}$ determines the real rate of return available from holding money as the nominal rate of interest on money minus the expected rate of inflation.

Various hypotheses are now introduced regarding the formation of expectations and also the value of $R N$. The alternative hypotheses are studied under four headings:

\section{Case 1}

Suppose that $R N=0$ and that expectations are formed adaptively by the relations:

$$
\begin{aligned}
& \pi=\pi_{-1}+\beta\left(\dot{p}_{-1}-\pi_{-1}\right) \\
& \dot{p}=\ln p-\ln p_{-1}
\end{aligned}
$$

where $\dot{p}$ denotes the rate of inflation and $\ln p$ the natural logarithm of the price level. Since the expected rate of inflation is assumed to adjust to the difference between the rate of inflation and expected rate of inflation in the previous period we obtain:

$$
\pi_{t}=\dot{p}_{0}(1-\beta)^{t}+\beta \sum_{i=0}^{t-1}(1-\beta)^{i} \dot{p}_{t-1-i}
$$

Thus the expected rate of inflation is determined by past values of the rate of inflation with geometrically declining weights. In this specification the parameter $\beta$ measures the response of the expected rate of inflation to the actual rate of inflation. It is bounded by $(0,1)$, and if $\beta$ equals unity the expected rate of inflation equals the rate of inflation in the previous period. Finally, note that the average time lag in adjustment equals $(1-\beta) / \beta$.

To study the behaviour of prices over time, reduce the system of Equations 1 and 2 to a second-order difference equation:

$$
\begin{aligned}
\ln p= & (1-\beta+\lambda \beta) \ln p_{-1}-\lambda \beta \ln p_{-2}-\beta \mathrm{a}-\eta \ln y+\eta(1-\beta) \ln y_{-1} \\
& +\ln M-(1-\beta) \ln M_{-1}
\end{aligned}
$$

which can be solved for the time path of $\ln p_{t}$ given the time paths of $\ln y_{t}$ and $\ln M_{t}$ and the initial conditions $\ln p_{0}$ and $\ln p_{1} \cdot{ }^{3}$ For the purposes of analysis suppose that initially real income and

${ }^{2} \mathrm{See}$ Appendix for the definition of money and of $R N$.

${ }^{3}$ For the derivation of this equation and discussion of related problems see Cagan (1956), Dutton (1971) and Akyüz (1973). 
money both stay constant over time so that $\ln y=\ln y_{-1}$ and $\ln M=\ln M_{-1}$. Denoting the resultant constant coefficient by $D \equiv-\beta a-\beta \eta \ln y+\beta \ln M$, we can write the difference equation as

$$
\ln p=(1-\beta+\lambda \beta) \ln p_{-1}-\lambda \beta \ln p_{-2}+D
$$

which has the solution

$$
\ln p_{t}=A_{1} \mu_{1}^{t}+A_{2} \mu_{2}^{t}+D / \beta
$$

where

$$
\begin{aligned}
& \mu_{1}=\left((1-\beta+\lambda \beta)+\sqrt{1-\beta+\lambda \beta)^{2}-4 \lambda \beta}\right) / 2 \\
& \mu_{2}=\left((1-\beta+\lambda \beta)-\sqrt{(1-\beta+\lambda \beta)^{2}-4 \lambda \beta}\right) / 2 \\
& A_{1}=\left(1+\left(\mu_{2}-\mu_{1}\right)\right)\left[\mu_{2}\left(\ln p_{0}-D / \beta\right)-\left(\ln p_{1}-D / \beta\right)\right] \\
& \left.A_{2}=\left(1 /\left(\mu_{2}-\mu_{1}\right)\right)\left[-\mu_{1}\left(\ln p_{0}-D / \beta\right)+\ln p_{1}-D / \beta\right)\right] .
\end{aligned}
$$

Thus the time path of prices will be convergent to its long-run solution given by $\ln p^{*}=$ $-a-\eta \ln y+\ln M$ if the stability conditions $\left|\mu_{1}\right|<1$ and $\left|\mu_{2}\right|<1$ are satisfied. ${ }^{4}$

Case 2

Suppose that $R N=0$ over time and that the expected rate of inflation adjusts to the difference between the rate of inflation this period and expected rate of inflation in the previous period. Given

$$
\pi=\pi_{-1}+\beta\left(\dot{p}-\pi_{-1}\right)
$$

we obtain

$$
\pi=\dot{p}_{0}(1-\beta)^{t}+\beta \sum_{i=0}^{t-1}(1-\beta)^{i} \dot{p}_{t-1} .
$$

The system of equations consisting of Equations 1 and 4 can now be reduced to a difference equation of first order

$$
\begin{aligned}
\ln p= & \left(\frac{1-\beta-\beta \lambda}{1-\beta \lambda}\right) \ln p_{-1}-\frac{\beta a}{1-\beta \lambda}-\left(\frac{\eta}{1-\beta \lambda}\right) \ln y+\left(\frac{1-\beta}{1-\beta \lambda}\right) \ln y_{-1} \\
& +\left(\frac{1}{1-\beta \lambda}\right) \ln M-\left(\frac{1-\beta}{1-\beta \lambda}\right) \ln M_{-1}
\end{aligned}
$$

which can be solved for the time path of $\ln p$ given the time path of $\ln y$ and $\ln M$ and the initial condition $\ln p_{0}$. For the purposes of analysis, suppose again that both real income and money remain constant over time so that the difference equation can be written as

$$
\ln p=\left(\frac{1-\beta-\beta \lambda}{1-\beta \lambda}\right) \ln p_{-1}+Z
$$

${ }^{4}$ This stability condition presupposes that roots are real and distinct. In the case of complex roots the stability of the system requires that $\beta \lambda<1$. 
where

$$
Z=-\frac{\beta a}{1-\beta \lambda}-\frac{\beta \eta}{1-\beta \lambda} \ln y+\frac{\beta}{1-\beta \lambda} \ln M
$$

This difference equation has the solution

$$
\ln p=\left(\ln p_{0}-Z\right)\left(\frac{1-\beta-\beta \lambda}{1-\beta \lambda}\right)^{t}+Z
$$

Hence the system will approach its long run solution given by

$$
\ln p^{*}=-a-\eta \ln y+\ln M
$$

as the stability condition

$$
\left|\frac{1-\beta-\beta \lambda}{1-\beta \lambda}\right|<1
$$

is satisfied. ${ }^{5}$

\section{Case 3}

Suppose that $R N>0$ over time and that expectations are formed adaptively by Equation 2 . The system of equations consisting of Equations 1 and 2 can now be reduced to:

$$
\begin{aligned}
\ln p & =-a-\eta \ln y-\lambda R+\ln M \\
R & =R N-\pi \\
\pi & =(1-\beta) \pi_{-1}+\beta * \ln p_{-1}-\beta z_{-1} \\
z & =\ln p_{-1} .
\end{aligned}
$$

Given the time path of $R N, \ln y$ and $\ln M$ and the initial conditions on $\ln p$ and $\pi$ we can determine the time path of $\ln p$ and $\pi$ by solving the system of Equation 6 simultaneously.

\section{Case 4}

Suppose that $R N>0$ over time and that expectations are formed adaptively by Equation 4 . The system of equations consisting of Equations 1 and 4 can be reduced to:

$$
\begin{aligned}
& \ln p=-a-\eta \ln y-\lambda R+\ln M \\
& R=R N-\pi \\
& \pi=(1-\beta) \pi_{-1}+\beta \ln p-\beta \ln p_{-1}
\end{aligned}
$$

Given the time path of $R N, \ln y, \ln M$ and the initial conditions on $\ln p$ and $\pi$ we can determine the time path of $\ln p$ and $\pi$ by solving the system of Equation 7 simultaneously.

${ }^{5}$ For a related study see Düger (1983). 
Thus far the demand for real money balances equation has been presented as an 'equilibrium' relationship, but in the real world economic units will not always be on their long-run demand schedules. The presence of incomplete information implies that adjustment of the dependent variable will not be instantaneous. To incorporate the pattern and length of such time lags we specify the equations within the framework of a general distributed lag model with geometrically declining weights. In particular, assuming real money balances to adjust to the difference between demand for real balances given by Equation 1a and actual real money balances in the previous period

$$
\ln (M / p)_{t}-\ln (M / p)_{t-1}=\delta\left(\ln (M / p)_{t}^{d}-\ln (M / p)_{t-1}\right)
$$

we obtain

$$
\ln (M / p)_{i}=\ln (M / p)_{0}(1-\delta)^{t}+\delta \sum_{i=0}^{i}(1-\delta)^{i} \ln (M / p)_{t-i}^{d}
$$

where the parameter $\delta$ measures the response of actual real money balances to demand for real money balances.

\section{ESTIMATION RESULTS}

In this section the estimation results of the money demand function for Turkey are presented. The analysis uses annual data covering the period 1960-83. The results are summarized in Tables 1 and 2 . The tables show the estimated coefficients with their respective $t$-values in parentheses below, the coefficient of determination and the Durbin-Watson statistic. In the tables CORC denotes the Cochrane-Orcutt iterative procedure and MA(1) the first-order moving average process. ${ }^{6}$

As emphasized in the previous section, the money demand function is estimated using two alternative specifications for the expected rate of inflation. First Equation 2 was used to construct different series for the expected ratio of inflation considering alternative values of $\beta \in[0,1]$. Ten different values of $\beta$ were considered starting from $\beta=0.1$. Each of the expected rate of inflation series was used to estimate the real rate of return obtained from holding money, which in turn was inserted in the money demand functions (Equations 1a and 8a). The value of $\beta$ to be choosen is that which maximizes $R^{2}$.

First consider Case 1 under the equilibrium assumption. In this case, when the OLS method is employed positive serial correlation resulted. Satisfactory results were obtained when the Cochrane-Orcutt procedure of correcting for first-order autoregressive disturbances were used. Similarly MA(1) yields satisfactory results. Analysis of the ACF and PACF functions for the OLS residuals do not lead to a clear-cut choice between an AR(1) or MA(1) specification. Therefore the estimation results for both specifications in Table 1 for the optimal value of $\beta$ are reported which in the present case equals unity. The income elasticity and the coefficient reflecting the effects of changes in the expected rate of inflation on the demand for money carry the expected signs and are significantly different from zero at the $5 \%$ level. The estimated value

${ }^{6}$ For a good discussion of estimation with AR(1) and MA(1) errors see Judge et al. (1985). 


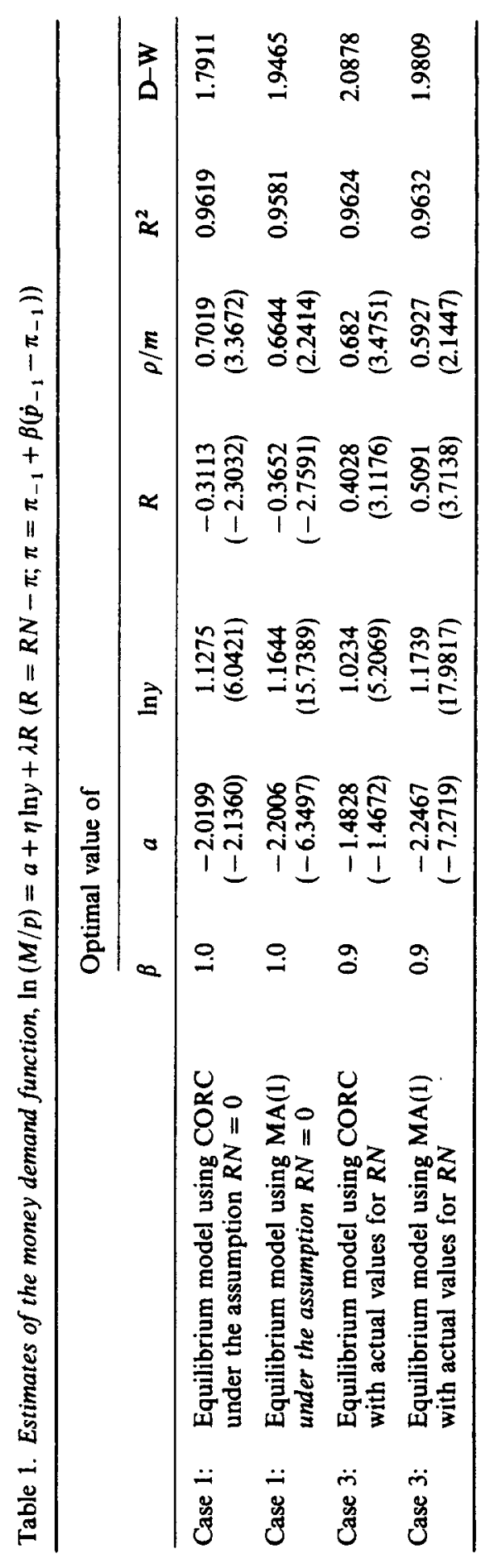


of the income elasticity equals 1.127 under CORC and 1.164 under MA(1). Similarly, the elasticity of the demand for money with respect to expected inflation rate equals $-0.311 * \pi$ under CORC and $-0.365 * \pi$ under MA(1).

Next Case 1 was considered under the disequilibrium assumption. In this case, when the OLS method was employed positive serial correlation resulted. Under CORC the estimated value of the parameter $\delta$ measuring the response of actual real money balances to demand for real money balances is not significantly different from zero. Similarly under MA(1), the estimated values of income elasticity of the demand for money and of the coefficient measuring the effect of changes in the expected rate of inflation on the demand for money are not significantly different from zero. Thus satisfactory results were not obtained with OLS, CORC or MA(1). Hence they are not reported.

Now turn to the analysis of Case 2. When the equilibrium assumption was employed, it was noted that positive serial correlation under both OLS and CORC resulted. Satisfactory results are obtained under MA(1). The estimation results for the optimal value of $\beta=0.5$ are summarized in Table 2 . The coefficients have the expected signs and are significantly different from zero at the $5 \%$ level. The estimated value of the income elasticity equals 1.398 and the elasticity of the demand for money with respect to expected inflation is $-0.933 * \pi$.

Consideration of Case 2 under the disequilibrium assumption reveals that OLS, CORC and MA(1) lead to unsatisfactory results. Under OLS positive serial correlation results, and under CORC and MA(1) the estimated values of the parameter $\delta$ turn out to be not significantly different from zero. Hence the results are not reported.

Turning to Case 3 under the equilibrium assumption it was noted that incorporation of the rate of interest on money in the money demand function improves the results considerably. OLS again indicates positive serial correlation, but satisfactory results are obtained under both CORC and MA(1). Analyses of the ACF and PACF functions for the OLS residuals again do not lead to a clear-cut choice between an AR(1) or MA(1) specification. Therefore the estimation results for both specifications are reported. The estimation results are summarized in Table 1 for the optimal value of $\beta$ which now equals 0.9 . The estimated values of $\eta$ and $\lambda$ have the expected signs and are significantly different from zero at the $5 \%$ level. For $\beta=0.9$ the estimated value of the income elasticity equals 1.023 under CORC and 1.174 under MA(1). Similarly, the estimated value of $\lambda$ equals 0.403 under CORC and 0.509 under MA(1).

Consideration of Case 3 under the disequilibrium assumption leads to unsatisfactory results. When the OLS method was employed positive serial correlation resulted. Under CORC and MA(1) the estimated values of the parameter $\delta$ are not significantly different from zero. Therefore the estimation results obtained using OLS, CORC and MA(1) are not reported.

Next consider Case 4 under the equilibrium assumption. Now both OLS and CORC indicate positive serial correlation. Satisfactory results are obtained using MA(1). The result is summarized in Table 2 for the optimal value of $\beta$ which equals 0.3 . The coefficients have the expected signs and are significantly different from zero at the $5 \%$ level. The estimated value of the income elasticity equals 1.423 and the elasticity of the demand for money with respect to the rate of real return available from holding money is $1.509_{*} R$.

As a final case, consider Case 4 under the disequilibrium assumption. In this case, satisfactory results were obtained using MA(1). The result for the optimal value of $\beta=0.4$ is presented in Table 2 . The coefficients again have the expected signs and are significantly different from zero at 


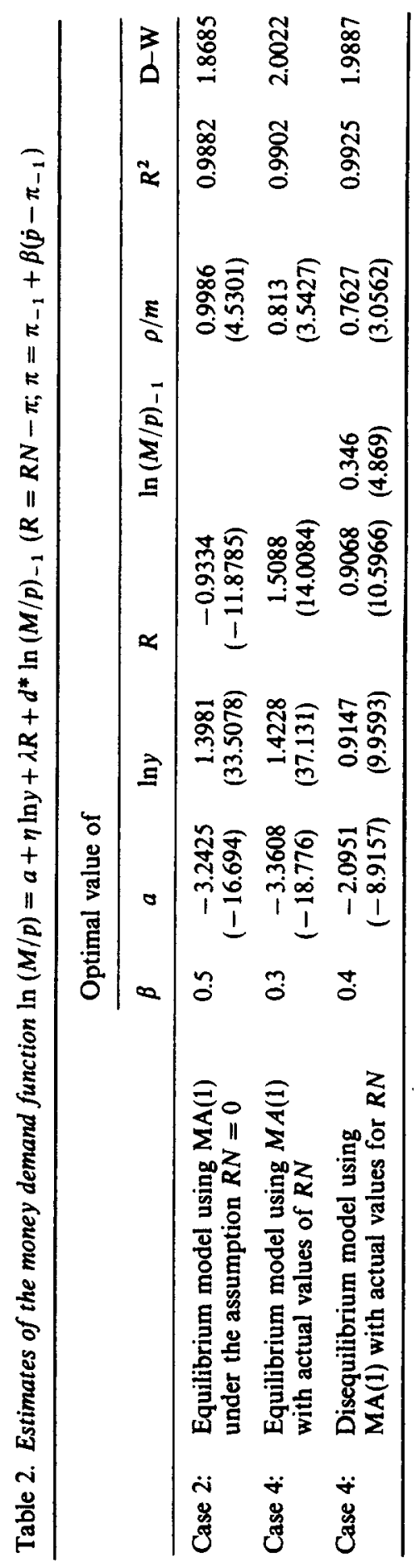


the $5 \%$ level. The estimated value of long-run income elasticity equals 1.399 and the long-run elasticity of the demand for money with respect to the rate of real return available from holding money is $1.386 * R$.

\section{SIMULATION RESULTS}

From the estimation results presented in the previous section, it follows that we end up with a set of income elasticities and a set of coefficients indicating the response of money demand to changes in real rate of return available from holding money. To choose from this set of parameter values simulation exercises are performed to obtain the mean absolute errors in predicting the rate of inflation for each of the cases considered.

Consider first Case 1 . Note that the parameter values of $(a, \eta, \lambda, \beta)$ have been estimated using CORC and MA(1) and not OLS. Hence the estimated parameter values cannot be inserted directly into the difference Equation 3 and solved for $\ln p$. It is clear that under CORC when the demand function is written as

$$
\ln (M / p)=a(1-\rho)+\eta\left(\ln y-\rho \ln y_{-1}\right)-\lambda\left(\pi-\rho \pi_{-1}\right)+\rho \ln (M / p)_{-1}+\varepsilon
$$

the error term $\varepsilon$ has zero mean and constant variance. Hence, for purposes of simulation with the parameter values estimated under CORC, the difference Equation 3 has to be written as the following system of equations:

$$
\begin{aligned}
\ln p & =\rho \ln p_{-1}+\lambda \pi-\rho \lambda \pi_{-1}+\left(\ln M-\rho \ln M_{-1}-\eta \ln y+\rho \ln y_{-1}\right)-a(1-\rho) \\
\pi & =\beta \ln p_{-1}+(1-\beta) \pi_{-1}-\beta z_{-1} \\
z & =\ln p_{-1}
\end{aligned}
$$

Given the actual values of $\ln M$ and $\ln y$ over the sample period the above system of equations is solved for the time paths of $(\ln p, \pi, Z)$. Denoting the predicted value of $\ln p$ by $\ln p s$ determine the predicted value of the rate of inflation by $\dot{p}^{s}=\left(\ln p s-\ln p s_{-1}\right)$. Finally, compare the estimated rate of inflation with the actual rate of inflation by determining the mean absolute error as:

$$
M A E=\sum_{i=0}^{T}\left|\dot{p}_{t}^{s}-\dot{p}_{t}\right| / T
$$

Consider now the parameter values of $(a, \eta, \lambda, \beta)$ estimated for Case 1 using MA(1). Recall that in a model with MA(1) errors, serial correlation is of the form

$$
u_{t}=v_{t}+m v_{t-1}
$$

where $m$ is a fixed parameter and the time series $\left(., v_{t-1}, v_{t}, \ldots\right)$ is a sequence of identically and independently distributed random disturbances with mean zero and constant variance. Hence the money demand function can be written as:

$$
\ln (M / p)=a+\eta \ln y-\lambda \pi+v+m v_{-1}
$$

Given the parameter values of $(a, \eta, \lambda, m)$ reported in Table 1 and the actual time paths of 
$(\ln M, \ln p, \ln y, \pi)$ it is possible to use the equation

$$
v_{t}=-m v_{t-1}+\left(\ln M_{t}-\ln p_{t}-a-\eta \ln y_{t}+\lambda \pi\right)
$$

together with the initial condition $v_{0}=0$ to determine the time path of $v_{t}$. Once $v_{t}$ is determined the approximate best, linear and unbiased predictor is given according to Judge et al. (1985) by

$$
\ln (M / p)=a+\eta \ln y-\lambda\left(\ln p_{-1}-\ln p_{-2}\right)+m v_{-1}
$$

Hence the difference equation determining the time path of prices can be written as follows:

$$
\begin{aligned}
\ln p= & (1-\beta+\lambda \beta) \ln p_{-1}-\lambda \beta \ln p_{-2}-\beta a-\eta \ln y+\eta(1-\beta) \ln y_{-1} \\
& +\ln M-(1-\beta) \ln M_{-1}-m v_{-1}+(1-\beta) m v_{-2}
\end{aligned}
$$

From this equation the time path of $\ln p$ denoted by $\ln p s$, and the predicted rate of inflation by $\dot{p}^{s}=\left(\ln p s-\ln p s_{-1}\right)$ is determined. The mean absolute error is then determined again by Equation 10.

Turn now to the analysis of Case 2. Since a model with MA(1) errors is again under consideration use the equation,

$$
v_{t}=-m v_{t-1}+\left(\ln M_{t}-\ln p_{t}-a-\eta \ln y_{t}+\lambda \pi_{t}\right)
$$

together with the initial condition $v_{0}=0$ to determine the time path of $v_{t}$. Given $v_{t}$ we derive from the money demand function

$$
\ln M-\ln p=a+\eta \ln y-\lambda \pi+m v_{-1}
$$

the difference equation determining the time path of prices as follows,

$$
\begin{aligned}
\ln p= & \left(\frac{1-\beta-\beta \lambda}{1-\beta \lambda}\right) \ln p_{-1}-\frac{\beta a}{1-\beta \lambda}-\left(\frac{\eta}{1-\beta \lambda}\right) \ln y+\left(\frac{\eta(1-\beta)}{1-\beta \lambda}\right) \ln y_{-1} \\
& +\left(\frac{1}{1-\beta \lambda}\right) \ln M-\left(\frac{1-\beta}{1-\beta \lambda}\right) \ln M_{-1}-\left(\frac{m}{1-\beta \lambda}\right) v_{-1}+\left(\frac{m(1-\beta)}{1-\beta \lambda}\right) v_{-2}
\end{aligned}
$$

This equation can now be used to determine the time path of predicted prices and rate of inflation.

Similar calculations were conducted for Cases 3 and 4 . The results of these exercises are reported in Table 3. From Table 3 it follows that the minimum value of mean absolute error is obtained under Case 3 using MA(1) (Case 3, Equilibrium model, MA(1), actual $R N$ ). The model tracks the movements in the rate of inflation rather closely as one can see from Fig. 1, and the mean absolute error in predicting the rate of inflation is $5.29 \%$.

Thus far, simulations were carried out dynamically in the sense that lagged endogeneous variables in the system of equations such as Equation 9 were themselves solutions of the same system in the previous periods. Alternatively the values of lagged endogeneous variables can be set equal to their actual values and the system of equations is solved accordingly. The simulations obtained by setting all exogeneous and lagged endogeneous variables equal to their actual values are called static simulations. The results of these simulations are reported in Table 4. 
Money, interest and inflation in a repressed economy

Table 3. Predicted rates of inflation under dynamic simulation

\begin{tabular}{lllllrrrr}
\hline & Actual & Case A & Case B & Case C & Case D & Case E & Case F & Case G \\
\hline 1965 & 4.2 & 15.3 & 12.1 & 15.3 & 13.5 & 9.9 & 9.0 & 29.5 \\
1966 & 6.2 & 9.2 & 5.2 & 10.9 & 6.5 & 3.0 & -4.6 & -10.3 \\
1967 & 6.3 & 10.4 & 10.8 & 11.1 & 10.4 & 10.8 & 24.8 & 21.6 \\
1968 & 3.8 & 7.5 & 4.0 & 7.4 & 3.7 & 3.8 & -13.1 & -8.6 \\
1969 & 5.2 & 7.99 & 7.6 & 7.9 & 6.7 & 9.0 & 21.7 & 14.9 \\
1970 & 11.2 & 10.9 & 9.3 & 11.1 & 9.5 & 6.6 & -4.0 & 18.0 \\
1971 & 16.8 & 12.1 & 13.4 & 13.2 & 13.5 & 8.1 & 20.3 & 18.9 \\
1972 & 15.1 & 15.8 & 17.9 & 16.9 & 17.9 & 11.7 & 13.6 & 13.3 \\
1973 & 19.97 & 18.6 & 16.8 & 19.7 & 17.4 & 16.0 & 23.2 & 20.2 \\
1974 & 24.97 & 16.2 & 18.2 & 17.0 & 17.9 & 9.4 & 8.1 & 14.4 \\
1975 & 15.0 & 14.99 & 19.1 & 15.7 & 18.3 & 16.8 & 26.5 & 21.7 \\
1976 & 15.5 & 14.2 & 11.1 & 14.9 & 10.9 & 15.0 & 3.5 & 7.2 \\
1977 & 21.9 & 21.3 & 24.1 & 21.7 & 24.1 & 16.6 & 37.4 & 28.5 \\
1978 & 36.3 & 28.7 & 27.7 & 29.1 & 28.8 & 25.0 & 18.5 & 25.0 \\
1979 & 53.7 & 43.1 & 49.5 & 43.4 & 48.9 & 26.1 & 65.8 & 56.7 \\
1980 & 71.2 & 55.6 & 59.3 & 55.8 & 58.8 & 44.3 & 45.0 & 55.1 \\
1981 & 34.98 & 57.4 & 65.9 & 53.7 & 57.1 & 33.5 & 33.1 & 48.9 \\
1982 & 24.2 & 46.4 & 25.7 & 43.3 & 22.4 & 74.7 & 45.0 & 23.8 \\
1983 & 24.7 & 26.2 & 24.2 & 28.6 & 33.4 & 0.6 & 30.3 & 30.6 \\
Mean & & & & & & & & \\
error & & 8.17 & 5.49 & 8.09 & 5.29 & 10.2 & 11.6 & 10.8 \\
\hline
\end{tabular}

Actual: Actual rate of inflation; Case A: Case 1, Equilibrium model, CORC, $R N=0$; Case B: Case 1, Equilibrium model, MA(1), $R N=0$; Case C: Case 3, Equilibrium model, CORC, actual $R N$; Case D: Case 3, Equilibrium model, MA(1), actual $R N$; Case E: Case 2, Equilibrium model, $\mathrm{MA}(1)$ and $R N=0$; Case F: Case 4, Equilibrium model, MA(1) and actual $R N$; Case G: Case 4, Disequilibrium model, MA(1) and actual $R N$.

Table 4 indicates that even under static simulation, Cases 2 and 4 lead to rather unsatisfactory results. Hence it can be concluded that the adaptive expectations, model of the form

$$
\pi=\pi_{-1}+\beta\left(\dot{p}_{-1}-\pi_{-1}\right)
$$

is preferable to the alternative form

$$
\pi=\pi_{-1}+\beta\left(\dot{p}-\pi_{-1}\right)
$$

From Table 4 it follows that under static simulation the minimum value of mean absolute error is obtained under Case 3 using CORC (Case 3, Equilibrium model, CORC, actual RN). The model tracks the movements in the rate of inflation satisfactorily as shown in Fig. 2, and the mean absolute error in predicting the rate of inflation amounts to $4.6 \%$.

Considering Case 3 with MA(1) and Case 3 with CORC as the appropriate specifications of the money demand function, note from Table 1 that the income elasticity of demand for money lies between the values of 1.023 and 1.174 , and that the elasticity of real money balances with respect to real rate of return available from holding money lies between $0.403_{*} R$ and $0.509_{*} R$. 


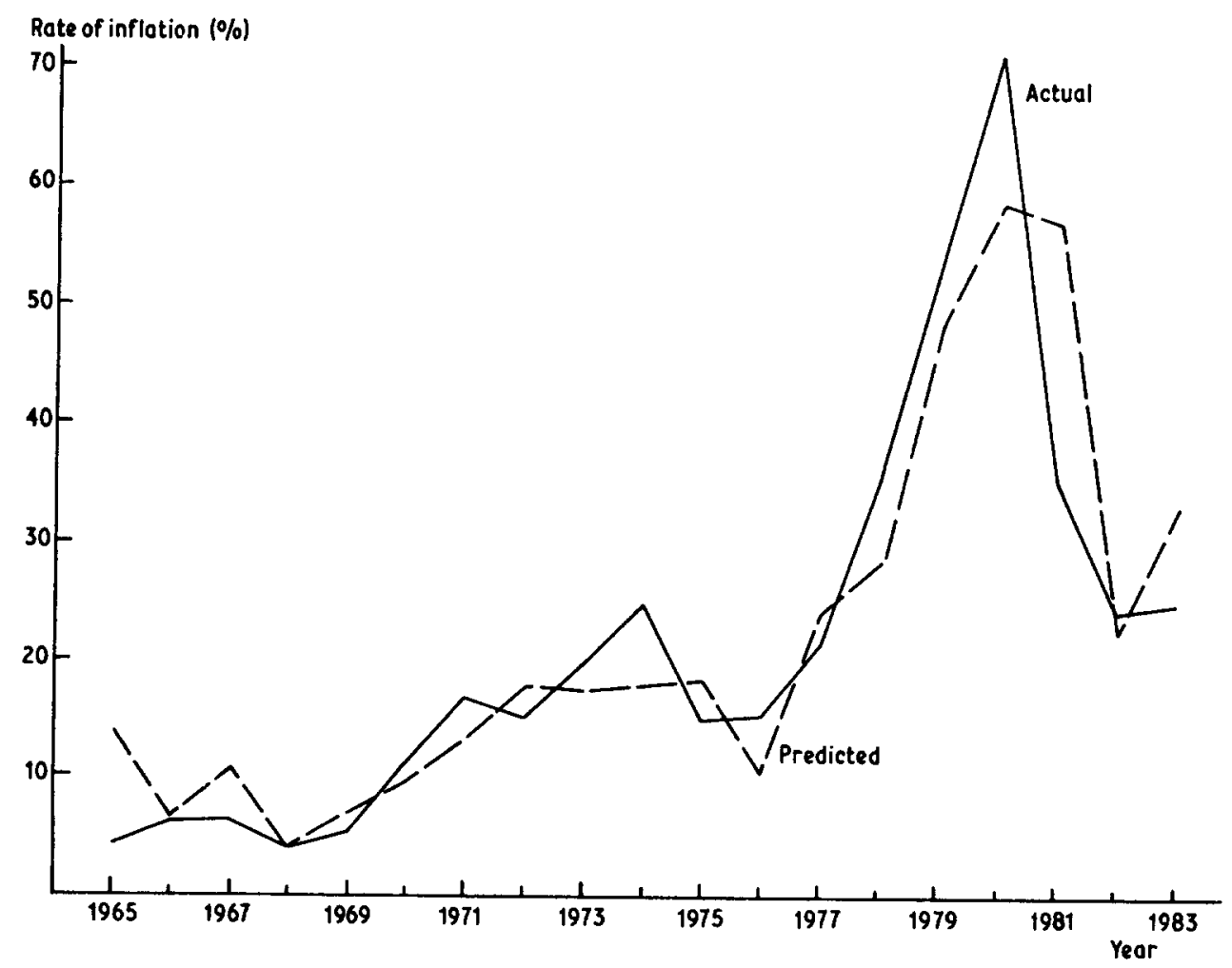

Fig. 1. Actual and predicted rates of inflation under dynamic simulation.

Turn now to the analysis of some policy experiments. Consider the equilibrium model under Case 3 estimated using MA(1). In this case Equation 3 is used. The equation determining the time path of prices can now be written using the parameter values reported in Table 1 as follows:

$$
\begin{aligned}
\ln p= & 0.55822 * \ln p_{-1}-0.45822 * \ln p_{-2}+(2.0220402-1.173916 * \ln y \\
& \left.+0.117391 * \ln y_{-1}-0.509134 * R N+0.050913_{*} R N_{-1}+\ln M-0.1 * \ln M_{-1}\right)
\end{aligned}
$$

Suppose initially that the system is in steady state with $\pi_{0}=\dot{p}_{0}=0.1$. Assume that $R N=0.04$, $y_{0}=100$ and $p_{0}=1 .^{7}$ The money demand function

$$
\ln (M / p)=-2.24671+1.17392 * \ln y+0.50913 *[R N-\pi]
$$

implies that in the initial period $t=0$,

$$
\ln M_{0}=3.1288
$$

\footnotetext{
${ }^{7}$ The parameter values of income $y_{0}=100$ and price level $p_{0}=1$ refer respectively to the mean value of income during the 1965-69 period and to the price level during 1968 .
} 
Money, interest and inflation in a repressed economy

Table 4. Predicted rates of inflation under static simulation

\begin{tabular}{lllllrrrr}
\hline & Actual & Case A & Case B & Case C & Case D & Case E & Case F & Case G \\
\hline 1965 & 4.2 & 9.0 & 3.9 & 6.4 & 4.8 & 7.1 & 7.6 & -22.0 \\
1966 & 6.2 & 6.7 & 6.3 & 5.4 & 5.2 & 2.9 & 1.1 & 24.2 \\
1967 & 6.3 & 12.8 & 13.0 & 11.4 & 13.4 & 14.9 & 18.7 & -1.7 \\
1968 & 3.8 & 9.0 & 9.4 & 8.0 & 9.4 & 1.4 & 3.0 & 7.0 \\
1969 & 5.2 & 11.0 & 14.2 & 9.9 & 14.0 & 16.4 & 19.3 & 6.5 \\
1970 & 11.2 & 14.9 & 17.9 & 14.0 & 17.7 & 10.1 & 13.6 & 7.2 \\
1971 & 16.8 & 16.8 & 21.4 & 17.1 & 21.7 & 24.4 & 22.0 & 18.6 \\
1972 & 15.1 & 19.7 & 23.2 & 20.5 & 24.1 & 13.8 & 19.0 & 16.6 \\
1973 & 19.97 & 20.2 & 22.5 & 20.8 & 23.6 & 27.1 & 27.6 & 16.3 \\
1974 & 24.97 & 19.1 & 23.0 & 20.2 & 24.1 & 16.6 & 17.9 & 20.4 \\
1975 & 15.0 & 17.2 & 18.3 & 19.1 & 20.4 & 17.5 & 14.9 & 24.4 \\
1976 & 15.5 & 12.1 & 10.5 & 12.6 & 10.8 & 2.7 & 3.3 & -0.2 \\
1977 & 21.9 & 21.1 & 22.2 & 21.9 & 22.5 & 25.9 & 23.1 & 39.1 \\
1978 & 36.3 & 27.8 & 25.5 & 29.5 & 27.2 & 23.5 & 26.2 & 16.2 \\
1979 & 53.7 & 42.8 & 42.7 & 45.6 & 46.4 & 62.9 & 64.0 & 78.6 \\
1980 & 71.2 & 51.0 & 46.7 & 56.9 & 55.4 & 62.9 & 76.7 & 52.4 \\
1981 & 34.98 & 49.0 & 44.1 & 54.3 & 52.2 & 44.7 & 25.7 & 57.01 \\
1982 & 24.2 & 31.9 & 19.2 & 23.6 & 13.1 & 21.3 & 23.3 & -1.3 \\
1983 & 24.7 & 26.6 & 29.9 & 25.5 & 28.8 & 31.1 & 25.8 & 41.8 \\
Mean & & & & & & & & \\
error & & 5.62 & 5.83 & 4.6 & 6.48 & 6.46 & 5.9 & 12.8 \\
\hline
\end{tabular}

Actual: Actual rate of inflation; Case A: Case 1, Equilibrium model, CORC, $R N=0$; Case B: Case 1, Equilibrium model, MA(1), $R N=0$; Case C: Case 3, Equilibrium model, CORC, actual $R N$; Case D: Case 3, Equilibrium model, MA(1), actual $R N$; Case E: Case 2, Equilibrium model, $\mathrm{MA}(1), R N=0$; Case F: Case 4, Equilibrium model, MA(1), actual $R N$; Case G: Case 4, Disequilibrium model, MA(1), actual $R N$.

and hence $M_{0}=22.84713$. Suppose that real income grows at the constant rate $r_{y}=0.05$. Then from

$$
r_{m}=\dot{p}+1.17392 * r_{y}
$$

it is derived that the money supply grows at the constant rate $r_{M}=0.158696$. Given the time path of $\ln M$ and $\ln y$ determined from the following equations

$$
\begin{aligned}
\ln y & =\ln y_{-1}+0.05, & \ln y_{0}=4.60517 \\
\ln M & =\ln M_{-1}+0.158696, & \ln M_{0}=3.1288
\end{aligned}
$$

and the time path of $R N$ as $R N_{t}=0.04$ for all $t \geqslant 0$ we can determine the time path of the exogeneous variable $X_{t}$ as follows:

$$
\begin{aligned}
X_{t}= & 2.0220402-1.173916 * \ln y_{t}+0.117391 * \ln y_{t-1}-0.509134 * R N_{t} \\
& +0.050913 * R N_{t-1}+\ln M_{t}-0.1 * \ln M_{t-1}
\end{aligned}
$$




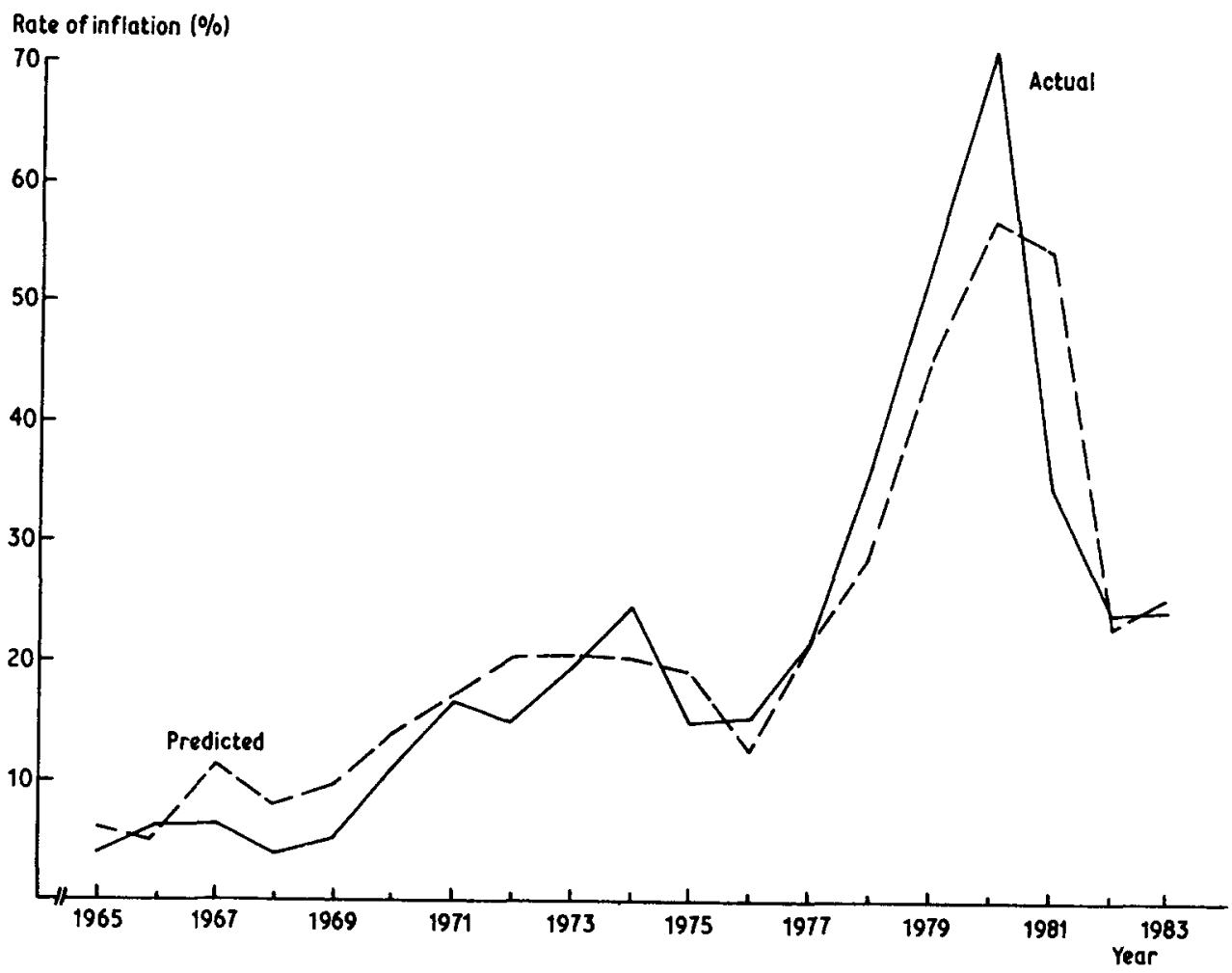

Fig. 2. Actual and predicted rates of inflation under static simulation.

Given $X_{q}$, determine the time path of prices from

$$
\begin{aligned}
& \ln p_{t}=0.55822 * \ln p_{t-1}-0.45822 * \ln p_{t-2}+X_{t} \\
& \ln p_{0}=0, \quad \ln p_{1}=0.1
\end{aligned}
$$

The solution, called the base solution, is characterized by the fact that the rate of inflation determined by the model is $10 \%$ for each of the periods considered.

Consider first a permanent increase in the rate of growth of the money supply. Suppose that the rate of growth of money supply increases from period one onwards by $10 \%$ from $15.8696 \%$ to $25.8696 \%$. As a result, the time path of the exogeneous variable $X_{t}$ and thus of $\ln p_{t}$ changes. The result of this experiment is reported in Table 5 as case A. From this table, it follows that the increase in the rate of growth of the money supply by $10 \%$ increases the rate of inflation initially by more than $10 \%$. This result is due to the fact that the increase in the rate of inflation increases the expected rate of inflation in the following period, which in turn decreases the real rate of return available from holding money. As a result, the velocity of money and hence the rate of inflation increases. The process will be reversed after a few periods when the expected rate of inflation starts to decrease. The system, after fluctuating around the new steady state value of the 
Table 5. Rate of inflation under alternative policy cases (\%)

\begin{tabular}{cllc}
\hline Year & Base case & Case A & Case B \\
\hline 0 & 10.0 & 10.0 & 10.0 \\
1 & 10.0 & 20.0 & 5.9268 \\
2 & 10.0 & 24.5822 & 8.1336 \\
3 & 10.0 & 22.5579 & 10.8245 \\
4 & 10.0 & 19.3282 & 11.3155 \\
5 & 10.0 & 18.4522 & 10.3565 \\
6 & 10.0 & 19.4442 & 9.5962 \\
7 & 10.0 & 20.3986 & 9.6111 \\
8 & 10.0 & 20.4772 & 9.968 \\
9 & 10.0 & 20.0837 & 10.1603 \\
10 & 10.0 & 19.828 & 10.1041 \\
11 & 10.0 & 19.8656 & 9.9846 \\
12 & 10.0 & 20.0037 & 9.9437 \\
13 & 10.0 & 20.0636 & 9.9756 \\
14 & 10.0 & 20.0338 & 10.0121 \\
15 & 10.0 & 19.9897 & 10.0179 \\
16 & 10.0 & 19.9787 & 10.0044 \\
17 & 10.0 & 19.9928 & 9.9942 \\
18 & 10.0 & 20.0057 & 9.9948 \\
19 & 10.0 & 20.0064 & 9.9997 \\
20 & 10.0 & 20.0009 & 10.0022 \\
\hline
\end{tabular}

Case A: Rate of growth of money supply increases by $10 \%$ from period 1 onwards.

Case B: Nominal rate of interest on money increases by $8 \%$ from period 1 onwards.

inflation rate, settles down to this new equilibrium value, which is determined from the system of Equations 1 and 2 as follows:

$$
\dot{p}=r_{m}-\eta_{*} r_{y} \quad R=R N-\pi \quad \pi=\dot{p}
$$

Thus the new equilibrium value of the inflation rate is $20 \%$.

Next consider the effect of a permanent increase in the nominal rate of interest on money $(R N)$. Suppose that real income and money grow respectively at their base values of $5 \%$ and $15.8696 \%$, and that the nominal rate of interest on money increases from period one onwards by $8 \%$ from $4 \%$ to $12 \%$. Since the rate of growth of the money stock and real income do not change by hypothesis, the steady state value of the rate of inflation will equal $10 \%$. As a result, the longrun real return on money increases from its initial value of $-6 \%$ to $+2 \%$. The result of this experiment is reported in Table 5 as case B. The table indicates that the increase in the nominal rate of interest on money decreases the rate of inflation substantially during the first two periods. The system fluctuates around its steady state value and settles down to the inflation rate of $10 \%$.

The above considerations can be summarized using Fig. 3. In this figure the AD schedule shows the aggregate demand schedule obtained from the money market equilibrium relation (Equation 1a) for given values of $R N$ and $\pi$. An increase in money supply shifts this schedule to 


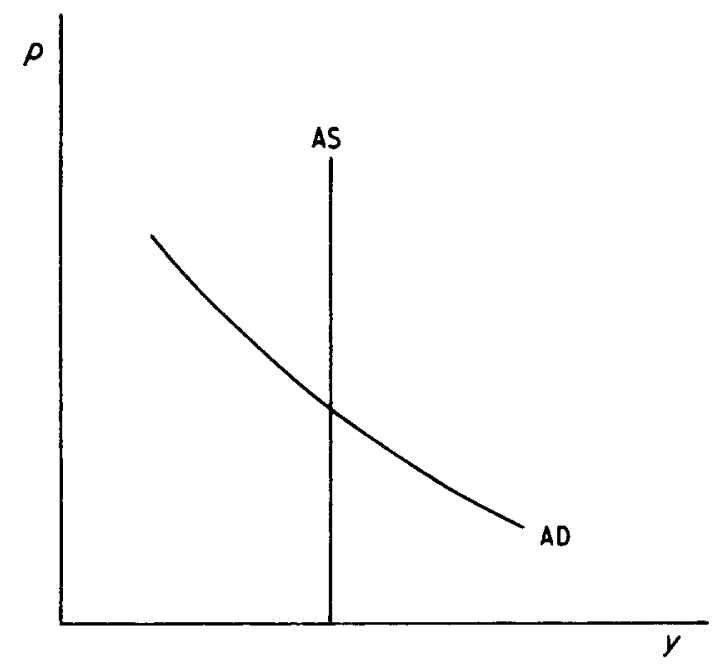

Fig. 3. Aggregate demand and aggregate supply schedules.

the right, whereas an increase in nominal rate of interest on money shifts the schedule to the left. Until now it has been assumed that the aggregate supply curve is price inelastic so that a change in money supply or the rate of interest does not affect the level of real income. The problem becomes more complex if there is an upward sloping supply schedule. The system consisting of aggregate demand and aggregate supply schedules have then to be solved simultaneously.

\section{CONCLUSIONS}

This paper provides an insight into the evolution of inflation in Turkey. Using a simple model for the demand for money it has been shown that the time path of money and interest rates does determine the movements in the rate of inflation in Turkey.

\section{APPENDIX: DATA SOURCES}

The sources for nominal GNP $(Y)$ and real GNP $(y)$ are various issues of Statistical Yearbook of Turkey, State Institute of Statistics, Turkey. The price level and rate of inflation have been obtained from the relations

$$
p=Y / y
$$

and

$$
\dot{p}=\ln p-\ln p_{-1}
$$


where $\ln p$ denotes the natural logarithm of the price level. The sources for money $(M)$, defined as currency in circulation plus demand plus time deposits, are various issues Quarterly Bulletin and Monthly Bulletin of the Central Bank of the Republic of Turkey. The nominal rate of interest on money $(R N)$ is obtained from the relation

$$
R N=r_{D *}(D D / M)+r_{T^{*}}(T D / M)
$$

where $r_{D}$ denotes the rate of interest on demand deposits, $r_{T}$ the rate of interest on time deposits, $D D$ demand deposits and $T D$ time deposits. The sources for nominal rates of interest on demand and time deposits and the shares of demand and time deposits in total money supply are various issues of the Quarterly Bulletin and Monthly Bulletin of the Central Bank of the Republic of Turkey.

\section{ACKNOWLEDGEMENTS}

I would like to thank Haluk Erlat and an anonymous referee of this journal for helpful comments and criticisms.

\section{REFERENCES}

Akyüz, Y. (1973) Money and Inflation in Turkey: 1950-1968, Ankara University, Faculty of Political Sciences, Ankara.

Cagan, P. (1956), The monetary dynamics of hyperinflation in Studies in the Quantity Theory of Money (Ed.) M. Friedman, University Press of Chicago, Chicago.

Dutton, D. S. (1971) The demand for money and the price level, Journal of Political Economy, 79, 1161-70. Düger, I. H. (1983) Inflation and Monetary Dynamics (Turkey: 1963-77), University of Anatolia, Eskisehir (in Turkish).

Judge, G. G., Griffith, W. E., Hill, R. C., Lutkepohl, H. and Lee, T. (1985) The Theory and Practice of Econometrics, John Wiley and Sons, New York. 
Copyright of Applied Economics is the property of Routledge and its content may not be copied or emailed to multiple sites or posted to a listserv without the copyright holder's express written permission. However, users may print, download, or email articles for individual use. 